\title{
EL LAGO DE LOS CURAS. MEDIACIÓN SOCIOPOLÍTICA Y CULTURAL EN LOS CORREGIMIENTOS DEL LAGO TITICACA (1570-1650)
}

\author{
THE LAKE OF PRIEST. SOCIO-POLITICAL AND CULTURAL \\ MEDIATION IN THE CORREGIMIENTOS OF THE LAKE \\ TITICACA (1570-1650)
}

Ariel J. Morrone

\begin{abstract}
Resumen
Este artículo analiza las prácticas sociales y políticas de los curas doctrineros encargados de la evangelización de los colectivos indígenas de los pueblos de reducción, englobados en los corregimientos del lago Titicaca entre fines del siglo XVI y mediados del siglo XVII. A partir de información contenida en protocolos notariales, expedientes judiciales y presentaciones ante instancias superiores de la administración colonial, indagamos el entramado del poder político local, toda vez que los curas doctrineros, junto a los caciques y los corregidores, conformaron las piezas claves en la dinámica política de cada pueblo de reducción.

Proponemos establecer puentes comparativos entre experiencias de construcción de carreras políticas tanto de curas como de autoridades indígenas, e interrogar las instancias de intermediación sociocultural protagonizadas por ambos actores sociales.
\end{abstract}

Palabras claves: Poder local - carrera política - liderazgo étnico territorialidad.

Abstract
This article analyzes social and political practices deployed by curas
doctrineros (rural priests) in charge of evaengelization of native
groups within the pueblos de reducción (villages) of the Titicaca lake
corregimientos (provinces) between the late-16th and the mid-17th
centuries. Notarial protocols, court records and formal presenta-
tions to higher colonial administration levels are addressed to in-
quire about local political framework, given that curas doctrineros,
as well as caciques and corregidores, played key roles in the political
dynamics of each pueblo de reducción. We prone to settle comparati-
ve approaches on how curas and caciques built their political careers
and to examine sociocultural intermediation instances carried out by both social actors.

Keywords: Local power - political career - ethnic leadership territoriality.

Recibido: diciembre 2015. Aceptado: marzo 2017.
La sistematización de un modelo de dominación colonial en el virreinato del Perú en torno al último cuarto del siglo XVI, fundamentalmente a partir del gobierno del virrey don Francisco de Toledo (1569-1581), corrió en paralelo a la consolidación del proyecto evangelizador derivado de los cánones del Concilio de Trento (1545-1563) y del III Concilio Limense (1583), cuyo objetivo fue garantizar la cristianización de la población nativa y su conversión a través del accionar de los así llamados "curas doctrineros". El reacomodamiento poblacional que implicó el traslado de los grandes contingentes nativos y su reducción a pueblos de indios, por un lado, y el establecimiento de las doctrinas rurales, a cargo de sacerdotes tanto regulares como seculares, por otro, pueden ser pensados, en gran medida, como procesos conjugados para lograr el sometimiento de las poblaciones andinas a las nuevas reglas del juego colonial, alterando sus pautas de organización territorial y sus prácticas de religiosidad (Estenssoro Fuchs 2003; Durston 2007; Ramos 2010).

En ese sentido, la reducción de los colectivos indígenas a pueblos de indios facilitaría el cobro de los tributos en especie y en dinero, la organización de la mano de obra (fundamentalmente para el abastecimiento del centro minero de Potosí, en pleno auge) y la evangelización de las almas en torno al culto dominical y la implementación de los sacramentos. Al menos en el plano del proyecto colonial, esta "vida en pulicía" en los pueblos de indios replicaba el ideal

1 Consejo Nacional de Investigaciones Científicas y Técnicas (CONICET) - Programa de Historia de América Latina (PROHAL), Instituto de Historia Argentina y Americana Dr. Emilio Ravignani, Facultad de Filosofía y Letras, Universidad de Buenos Aires. Dirección postal: 25 de Mayo 221, Piso 2, Ciudad de Buenos Aires, ARGENTINA. Email: arielmorri@yahoo.com.ar. 
hispano de la "comunidad civil" heredado de las tradiciones romana (la civis, en tanto cuerpo social, organizaba espacialmente la "vida civilizada", única vida posible) y cristiana (a partir del impulso del catolicismo contrarreformista de la época de Felipe II) (Málaga Medina 1974; Durston 19992000, 2007; Jurado 2004).

Pero las dinámicas sociales efectivamente desarrolladas en estos nuevos espacios distaron de replicar los mandatos emanados desde los distintos niveles de la autoridad colonial. A más de fungir como terminales efectivas del dispositivo evangelizador, los pueblos de reducción, las doctrinas y las iglesias rurales constituyeron espacios de articulación política a escala local, ámbitos de sociabilidad e instancias de negociación del poder, de circulación de bienes y de intermediación cultural, de modo análogo a lo acontecido en el escenario peninsular (Christian 1991; Nalle 1992). En este avance de investigación, continuamos indagando sobre el conjunto de prácticas sociales articuladas en torno a las iglesias rurales del sur andino, más específicamente aquéllas que quedaron englobadas en la jurisdicción de los corregimientos de indios adyacentes al lago Titicaca, dependientes de la ciudad de Nuestra Señora de La Paz, fundada en 1548 y sede episcopal desde 1609 (Morrone 2010, 2013a).

Concebir las iglesias, las doctrinas y los pueblos de reducción como componentes de la territorialidad colonial, implica conceptualizarlos como resultantes de la correlación de fuerzas entre distintas territorialidades en disputa por los mismos recursos (económicos, humanos y simbólicos, si cabe tal distinción). Esta perspectiva nos permite pensar las doctrinas como partes constitutivas del "hecho colonial", en la medida en que el dominio se apoyó en una fuerte apuesta a la cristianización de la población nativa "en el territorio", a través de la labor catequética de los curas doctrineros. Empero, esta visión "desde arriba" presenta un sesgo: difícilmente el desempeño de los curas doctrineros al frente de sus feligresías pudo lograr una conversión completa. Más bien, proponemos pensar las doctrinas como espacios de intermediación cultural, que si bien sustentaron la trama del dominio hispánico, habilitaron asimismo instancias de negociación política parcial donde la población nativa, sus autoridades étnicas y las propias autoridades coloniales (eclesiásticas, pero también laicas) construyeron sus carreras políticas, liderazgos y subjetividades a partir de la articulación de prácticas y relaciones sociales en virtud (o a través) del propio contacto interétnico.

En tiempos coloniales, los grupos de habla aymara que habitaban la cuenca del lago Titicaca (fundamentalmente, los lupaqa al oeste, los pakaxa al sur e incluso los kolla de habla puquina al norte, a más de una minoritaria población uru lacustre) se organizaron en torno a grupos parentales (ayllu) para la cría de ganado de altura y para el cultivo de tubérculos en las fértiles tierras adyacentes al lago. Este perfil socioproductivo agroganadero data de tiempos preincaicos, y fue intensificado por el breve período de dominio cusqueño. A partir del segundo tercio del siglo XVI, tanto la tierra como la mano de obra fueron progresivamente subsumidas por el sistema mercantil impuesto por el dominio hispánico en la región, produciendo importantes transformaciones en las pautas de organización colectivas, en las dinámicas sociodemográficas y territoriales y en los criterios de legitimidad de sus autoridades étnicas: los kuraka, mallku o, en términos generales, "caciques" (Murra 1988; Choque Canqui 1993). En este contexto, el trabajo apunta a reconstruir las relaciones entre las autoridades étnicas y los curas doctrineros; previo a ese análisis, presentaremos el escenario en el cual se entramaron esas relaciones.

\section{* Pueblos de Reducción y doctrinas en el lago TITICACA}

En el escenario surandino, las primeras décadas coloniales estuvieron signadas por los enfrentamientos entre las huestes conquistadoras, el reparto de los grandes bolsones de población y recursos entre las facciones circunstancialmente triunfadoras, la ocupación del espacio nativo a partir de la fundación de ciudades y el establecimiento de la encomienda como complejo práctico-institucional que regló los vínculos entre los flamantes vecinos encomenderos y las mayorías nativas encomendadas, nucleadas en torno a sus autoridades reconocidas como caciques de repartimiento. Asimismo, la puesta en producción de los yacimientos argentíferos de Porco (1538) y Potosí (1545) conllevó al rápido asentamiento español en el macizo de Charcas en torno a la recientemente fundada ciudad de La Plata y a la concentración forzada de la mano de obra indígena destinada al trabajo minero, sobre todo en el Cerro Rico de Potosí (Assadourian 1983; Presta 2000). 
En este contexto general, la fundación de la ciudad de Nuestra Señora de La Paz en 1548 en pleno altiplano aymara implicó un cambio en las relaciones políticas locales, en tanto su jurisdicción se extendería sobre los repartimientos de indios encomendados a los principales vecinos, imprimiendo así una nueva territorialidad al espacio circun-lacustre. Durante la "época de oro" de la encomienda en La Paz (1548-1565), los recursos de los grupos nativos emplazados en la cuenca del lago Titicaca fueron drenados hacia el nuevo segmento encomendero, cuyos miembros ejercieron un dominio directo de esa población a través del sometimiento (en algunos casos) o la colaboración (en otros) de las autoridades étnicas. Derivado de una merced real, el tributo, tanto en trabajo como en especie, fue la recompensa otorgada a los encomenderos por garantizar la protección y evangelización de la población nativa. El pago del salario de los curas doctrineros, en esta etapa inicial, quedó a cargo de los encomenderos, mientras que la población encomendada debería proveer a su sacerdote de alimentos y todo lo necesario para su sustento.
En materia religiosa, los colectivos indígenas nucleados bajo la jurisdicción de la ciudad de La Paz quedaron asociados al obispado y a la Audiencia de Charcas desde sus respectivas instalaciones (1552 y 1561). Con la Orden franciscana como la primera en establecerse en la ciudad (1549), en las décadas posteriores asistiremos a la fundación de los conventos de los padres agustinos (1562), mercedarios (1570), jesuitas (1582) y dominicos (1590) (López Beltrán 1998: 32-34; Finegan 1999: 32). La labor catequética de los religiosos paceños merece una mención especial, toda vez que el lago Titicaca ejercía, desde tiempos preincaicos incluso, una gran centralidad simbólica en las religiosidades nativas. Tanto el propio lago como los centros de peregrinaje de sus islas y el santuario de Copacabana habían sido sacralizados por el poder incaico e incorporados a la geografía ritual. Se trataba, pues, de un espacio sagrado de influencia regional a ser disputado por los curas doctrineros (Amselle 1985; Salles-Reese 1997; Bauer y Stanish 2001; Rostworowski 2003; Cruz 2009).

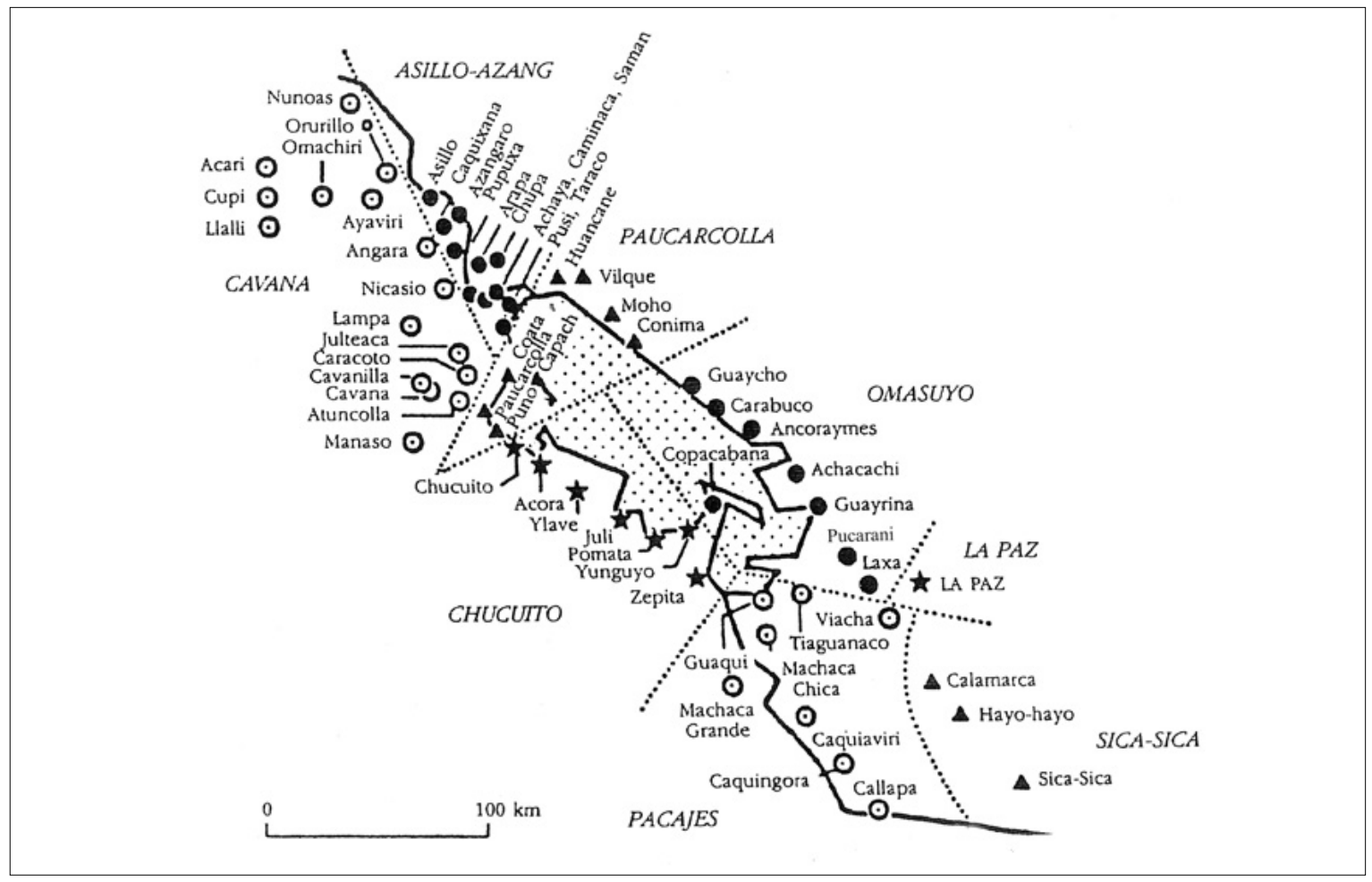

Figura 1. Corregimientos de indios y pueblos de reducción del lago Titicaca (intervenido a partir de Wachtel 2001 [1990]: 339). Los pueblos de reducción de cada corregimiento aparecen representados con íconos diferenciados. 
En cuanto a las jurisdicciones administrativas, la implementación de los corregimientos de indios en 1565 y el proceso de reducción a pueblos de indios en la década de 1570 complejizaron más aún las transformaciones territoriales atravesadas por los colectivos étnicos y, en gran medida, impuestas por un poder metropolitano con la intención de limitar el poder de las élites encomenderas, sistematizar y operativizar de forma más eficaz la estructuración del dominio colonial (ver Figura 1). El territorio indígena bajo jurisdicción de la ciudad de La Paz quedó fragmentado en cinco corregimientos (Sicasica, Pacajes, Omasuyos, Larecaja y Paucarcolla) y una gobernación (Chucuito). A cargo de un "corregidor y justicia mayor", cada una de estas unidades administrativas englobaba distinta cantidad de pueblos de reducción, a su vez dependientes de un "cacique principal y gobernador" y un conjunto de autoridades de menor jerarquía (segundas personas, alcaldes de indios, principales). Junto al corregidor y al cacique, los curas doctrineros conformaban los tres puntales que ataban los nudos del poder local y fungían de intermediarios entre las instancias superiores del poder colonial (cabildo, audiencia, virrey, orden religiosa, obispo) y los ayllu que conformaban cada pueblo (Saignes 1987). ${ }^{2}$

2 La coincidencia entre jurisdicciones eclesiásticas y seglares remitía a la Ordenanza 4 al Consejo de Indias, sancionada por
La sistematización del dominio colonial operada a partir de las reformas toledanas (1570-1575) implicó un cambio en la organización espacial de los colectivos indígenas y la imposición (parcial) de nuevos regímenes de territorialidad, anclados en los pueblos de reducción como dispositivo articulador de la tributación, la organización de la mano de obra y la evangelización. Empero, no todo fue imposición: en torno al proceso de reducción, españoles, los indígenas y sus autoridades disputaron y negociaron (con variables resultados) las nuevas territorialidades (Wernke 2007; Zuloaga Rada 2012; Zagalsky 2013). A los fines del presente trabajo, el ordenamiento toledano permite visualizar las plazas destinadas a los curas doctrineros y la composición de los sínodos (salarios derivados de la nueva tasa).

Felipe II en 1571, "teniendo siempre atencion á que la division para lo temporal se vaya conformando y correspondiendo quanto se compadeciere con lo espiritual". Recopilación de Leyes de Indias, Libro II, Título II, Ley VII.

\begin{tabular}{|c|c|c|c|c|c|c|}
\hline \multirow{2}{*}{ Corregimiento } & \multirow{2}{*}{ Repartimiento } & \multirow{2}{*}{ Pueblo de reducción } & \multirow{2}{*}{ Doc } & \multicolumn{3}{|c|}{ Sínodo (pesos ensayados) } \\
\hline & & & & Pueblo & Minas & Total \\
\hline \multirow{12}{*}{ Pacajes } & \multirow{3}{*}{ Callapa } & Santiago de Callapa & \multirow{3}{*}{$2[\dagger]$} & \multirow{3}{*}{1400} & \multirow{3}{*}{300} & \multirow{3}{*}{1700} \\
\hline & & San Pedro de Julloma & & & & \\
\hline & & San Pedro de Curaguara & & & & \\
\hline & \multirow{2}{*}{ Caquingora } & Santa Bárbara de Caquingora & \multirow{2}{*}{2} & \multirow{2}{*}{1400} & \multirow{2}{*}{400} & \multirow{2}{*}{1800} \\
\hline & & Nuestra Señora de Buena Esperanza de Calacoto & & & & \\
\hline & Caquiaviri & Concepción de la Nueva Toledo de Caquiaviri & $2[t]$ & 1100 & 461 & 1561 \\
\hline & Machaca la Chica & Jesús de Machaca & 1 & 600 & & 600 \\
\hline & \multirow{2}{*}{ Machaca la Grande } & San Andrés de Machaca & \multirow{2}{*}{2} & \multirow{2}{*}{1200} & \multirow{2}{*}{400} & \multirow{2}{*}{1600} \\
\hline & & Santiago de Machaca & & & & \\
\hline & Guaqui & Santiago de Guaqui & 2 & 1400 & 200 & 1600 \\
\hline & Tiwanaku & San Pedro de Tiwanaku & 1 & 700 & 150 & 850 \\
\hline & Viacha & San Agustín de Viacha & 1 & 700 & 250 & 950 \\
\hline
\end{tabular}


EL LAGO DE LOS CURAS. MEDIACIÓN SOCIOPOLÍTICA Y CULTURAL EN LOS CORREGIMIENTOS DEL LAGO TITICACA (1570-1650)

\begin{tabular}{|c|c|c|c|c|c|c|}
\hline \multirow{12}{*}{ Omasuyos } & Achacachi & \multirow{2}{*}{ Villa de Cáceres de Achacachi } & \multirow{2}{*}{2} & 1273 & 400 & 1673 \\
\hline & Quinaquitara & & & 127 & 13 & 140 \\
\hline & Guarina & \multirow{2}{*}{$\begin{array}{l}\text { Villa de Mérida / Nuestra Señora de la Encarnación } \\
\text { de Guarina }\end{array}$} & $2[\dagger]$ & 1084 & 416 & 1500 \\
\hline & Yaye & & 1 & 216 & 20 & 236 \\
\hline & Copacabana & Nuestra Señora de Copacabana & $1[\dagger]$ & 700 & 300 & 1000 \\
\hline & Laja & Nuestra Señora de la Concepción de Laja & 1 & 700 & 150 & 850 \\
\hline & Pucarani & Nuestra Señora de Pucarani & $2[\dagger]$ & 1400 & 300 & 1700 \\
\hline & Carabuco & Santa Cruz de Carabuco & 1 & 544 & 120 & 664 \\
\hline & Ancoraimes & \multirow{2}{*}{ Ancoraimes / Villa de Cangas } & \multirow{2}{*}{1} & 156 & 30 & 186 \\
\hline & Guancasco & & & 56 & 12 & 68 \\
\hline & Chuquiabo & San Pedro y Santiago de Chuquiabo & $1[\dagger]$ & 550 & 50 & 600 \\
\hline & Guaycho & Santiago de Guaycho & 1 & & & 700 \\
\hline \multirow{9}{*}{ Paucarcolla } & Capachica & San Salvador de Capachica & & 1050 & 200 & \\
\hline & Coata & [Nuestra Señora de Guadalupe] & (1) & 350 & & 政 \\
\hline & \multirow{2}{*}{ Puno } & San Juan de Puno & \multirow{2}{*}{2} & 650 & 300 & \multirow{2}{*}{1650} \\
\hline & & San Pedro de Icho & & & & \\
\hline & Guancané & Santiago de Guancané & 1 & 715 & & $715^{(*)}$ \\
\hline & \multirow{2}{*}{ Paucarcolla } & San Pedro de Paucarcolla & \multirow{2}{*}{2} & \multirow{2}{*}{1400} & \multirow{2}{*}{200} & \multirow{2}{*}{1600} \\
\hline & & San Francisco de Tiquillaca & & & & \\
\hline & Moho y Conima & San Pedro de Moho & 1 & 700 & 160 & $\left.8600^{* *}\right)$ \\
\hline & Vilque & San Pedro de Vilque & 1 & 350 & $30(* * *)$ & 380 \\
\hline \multirow{7}{*}{ Chucuito } & \multirow{7}{*}{ Chucuito } & San Pedro de Chucuito [ciudad] & 4 & 3340 & \multirow{7}{*}{1500} & \multirow{7}{*}{18690} \\
\hline & & San Pedro de Acora & 3 & 2340 & & \\
\hline & & San Miguel de Ilave & 3 & 2310 & & \\
\hline & & San Pedro de Juli & $4[\dagger]$ & 3200 & & \\
\hline & & Santiago de Pomata & $3[t]$ & 2310 & & \\
\hline & & Santa Cruz de Zepita & 3 & 2250 & & \\
\hline & & Santiago de Yunguyo & 2 & 1440 & & \\
\hline TOTALES & 28 & 37 & 57 & & & \\
\hline
\end{tabular}

Tabla 1. Organización eclesiástica a partir de la visita toledana ${ }^{3}$

Entendidas como conjuntos de población nativa nucleada bajo la guía pastoral de un cura (es decir, como jurisdiccio-

3 Fuentes: Maurtúa 1906, XI: 91-102 y 179-183; Cook 1975: 43-83. [†] Doctrinas a cargo del clero regular. $\left(^{*}\right)$ Corresponden a 562 pesos de oro fino, "reducido a plata ensayada con refaición de venticinco por ciento" (Cook 1975: 58). (**) Del total de 870 pesos ensayados, 543 correspondían a los tributarios de Moho y 317 a los

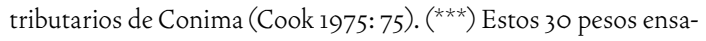
yados eran paga "para la comunidad de los yndios, en el entretanto que no se junta la dicha doctrina con la de Guancane". Archivo General de la Nación (AGN) Sala IX, 17-2-5, ff. 227v-228r. nes eclesiásticas), las doctrinas se organizaron al calor del proceso reduccional toledano (Adrián 1997; Lundberg 2011: 28-32; Ramos 2015). La Tabla 1 ilustra, ante todo, la diversidad de situaciones que coexistieron en la diócesis paceña. En primer lugar, constatamos que no existía una correlación directa entre pueblos de indios y doctrinas. En las cuatro jurisdicciones administrativas abordadas en este trabajo, el gobierno colonial estableció 37 pueblos de indios, cuyos habitantes eran doctrinados por 57 religiosos. En muchos casos, un único sacerdote estaba al frente de los feligreses de un pueblo de reducción, impartía los sacramentos y cumplía con el 
resto de sus obligaciones, aunque en otros había más de una plaza a ocupar (generalmente debido a cuestiones demográficas). Particular fue el caso del repartimiento de Callapa, por ejemplo, a partir del cual se fundaron tres pueblos con dos doctrinas, una para el de Santiago de Callapa y otra para los otros dos (San Pedro de Julloma y San Pedro de Curaguara).

En segundo lugar, verificamos una preeminencia de religiosos seculares por sobre los miembros de las órdenes religiosas: solo 18 de las 57 doctrinas (es decir, un 31\%) estaban a cargo de sacerdotes regulares: tres franciscanos (Chuquiabo y Caquiaviri), tres agustinos (Pucarani y Copacabana), tres dominicos (Pomata), cuatro jesuitas (Juli) y cinco mercedarios (Callapa, Julloma-Curaguara, Guarina, Capachica y Coata). ${ }^{4}$ Asimismo, notamos diferencias en la composición de los sínodos. El rango establecido en las matrículas tributarias varió en función del caudal demográfico y de la dotación productiva de los respectivos pueblos. Así, la mayoría de los sínodos era de 700 pesos ensayados; solo los correspondientes a las doctrinas de la gobernación de Chucuito superaban esa cifra. ${ }^{5}$ Por ser algunas plazas más "apetecibles" que otras, esta disparidad debió generar disputas entre los candidatos, quienes a su vez complementaban sus ingresos a través de la participación en negocios altamente beneficiosos con figuras de poder político y económico (Taylor 1999 [1996]: 205-209). ${ }^{6}$

Las doctrinas conformaron, en efecto, instancias de interacción política y sociocultural entre el personal eclesiástico

4 En su informe de 1627, el doctor don Pedro de Valencia, segundo obispo de La Paz, indicaba la existencia de 72 doctrinas, de las cuales 57 (es decir, un 79\%) conforman el universo de nuestro trabajo (Maurtúa 1906, XI: 178). Las doctrinas de Caquiaviri estuvieron a cargo de la orden franciscana desde la construcción de la iglesia en 1560 hasta 1581. El predominio del clero secular sobre el regular en el adoctrinamiento religioso de la población nativa paceña coincide con el escenario del vecino obispado de Arequipa (Hidalgo, Marsilli y Aguilar 2016).

5 En términos comparativos, señalamos que para la década de 1590 en La Paz, un caballo valía 500 pesos corrientes $(=312$ pesos 4 tomines ensayados) y una esclava adulta valía 700 pesos corrientes (= 437 pesos 4 tomines ensayados). Archivo de La Paz (ALP), Registro de Escrituras (RE), Caja 4 Legajo 4, ff. 136r-136v: Diego Rodríguez Franco; y C6 L9, ff. 277r-278r: Gaspar de Chaves.

6 Si bien situada en el escenario novohispano del siglo XVIII, la señera obra de William Taylor es incorporada aquí en virtud de los paralelismos registrados con la dinámica del campo religioso paceño del siglo XVII. destacado en ellas (los curas doctrineros), los grupos nativos bajo su jurisdicción, tanto la feligresía en general como sus caciques y otros nativos asociados al oficio religioso (sacristanes, fiscales, cantores, músicos y maestros de capilla). En tanto centros de decisión política, las doctrinas constituyeron escenarios claves para analizar la inserción territorial del clero en la sociedad local.?

¿Cuáles fueron, a nuestro entender, los componentes territoriales del proceso de cristianización de la población nativa? Las prácticas de sociabilidad y religiosidad se organizaron a partir de una secuencia espacial, desde el interior del edificio (altar central, nave principal) hacia el exterior más próximo (atrio, plaza) y zonas más alejadas (casco del pueblo, estancias) (Sack 1986: 92-95; Durston 1999-2000; González 2010). Estas distancias espaciales estaban íntimamente asociadas a otras, de orden ritual, en tanto cualquier paraje apartado de los asentamientos hispanizados fue considerado como amenaza al culto cristiano. Así entendido, el proceso reduccional tuvo un matiz de "adoctrinamiento espacial". Dado que solo existía una forma de vivir en "buena policía", el pueblo de indios constituía al mismo tiempo la representación del orden religioso frente al caos idolátrico (Estenssoro Fuchs 2003: 179-193). Pero, nuevamente, debemos refinar la mirada para ver más allá del proyecto cristianizador: ipodemos acaso interpretar los atrios como una versión colonial de las "plazas para los antepasados", es decir, un espacio de reactivación de solidaridades y cultos prehispánicos (Nielsen 2006)? ¿Qué roles cupieron a los curas y a los caciques en los nuevos procesos de socialización?

Proyectados desde sus respectivas iglesias, los curas doctrineros construyeron tramas de relaciones personales, políticas y económicas que, en buena medida, condicionaron su quehacer al frente de sus feligresías. Su formación, sus carreras y sus estilos de vida encarnaron tendencias posibles de ser delineadas a partir de la lectura cruzada de la documentación colonial (Taylor 1999 [1996]; Lundberg 2001; Hidalgo Lehuedé 2011). Allí dirigimos nuestra mirada, con la intención de (re)construir las trayectorias de los curas doctrineros que tuvieron acción en el lago Titicaca durante la primera mitad del siglo XVII.

7 Adrian 2000. Retomamos aquí la concepción de territorio como “el espacio 'equipado' desde el punto de vista político y administrativo" (Hespanha 1989: 83; Barriera 2006: 379). 


\section{* Los curas doctrineros: carreras político- ECLESIÁSTICAS Y NEGOCIOS}

Tal como mencionamos, el "orden toledano" sistematizó en gran medida la organización eclesiástica del mundo rural surandino. Sin embargo, la documentación aquí empleada para reconstruir el conjunto de prácticas tramadas por los curas doctrineros y las autoridades étnicas corresponde a principios del siglo XVII. ¿A qué obedece esta dispersión documental? Si bien la bula papal que erigió el Obispado de La Paz data de 1605, recién en 1609 quedaría establecida la fragmentación del Obispado de La Plata y la distribución de las respectivas doctrinas (ver Figura 2).

Más aún: el primer obispo de La Paz, el padre dominico fray Domingo de Valderrama y Centeno, llegó a la flamante sede episcopal en abril de 1610, ocupando el solio hasta su muerte en 1615. Tanto él como sus sucesores, don Pedro de Valencia (1616-1631) y don Feliciano de Vega y Padilla (1634-1639), serían los encargados de aceitar los mecanismos de control no solo sobre las poblaciones nativas, sino también de los propios curas doctrineros (Meiklejohn 1988: 77-84; Finegan 1999:34-37). Esta “activación" de los engranajes administrativos de la nueva diócesis explica, según creemos, la profusa documentación que hallamos a partir de 1610.

En el transitar de sus carreras político-eclesiásticas, los curas doctrineros pusieron en juego no solo sus habilidades y competencias individuales, sus méritos y conocimientos, sino también las tramas de vínculos sociales que cada uno había podido articular y acumular. Formación académica, desempeño en las pruebas de oposición, origen social y prosapia, manejo de lenguas nativas y reputación intachable figuraban entre las variables tenidas en cuenta por las altas jerarquías diocesanas a la hora de designar candidatos para cubrir beneficios vacantes por muerte, renuncia, permuta o traslado del anterior titular. Empero, la promoción de determinadas figuras del elenco clerical hacia determinadas posiciones en el engranaje diocesano (en detrimento de otras) también estaba atravesada por contactos personales y redes de poder, ancladas en el parentesco, el paisanaje y/o

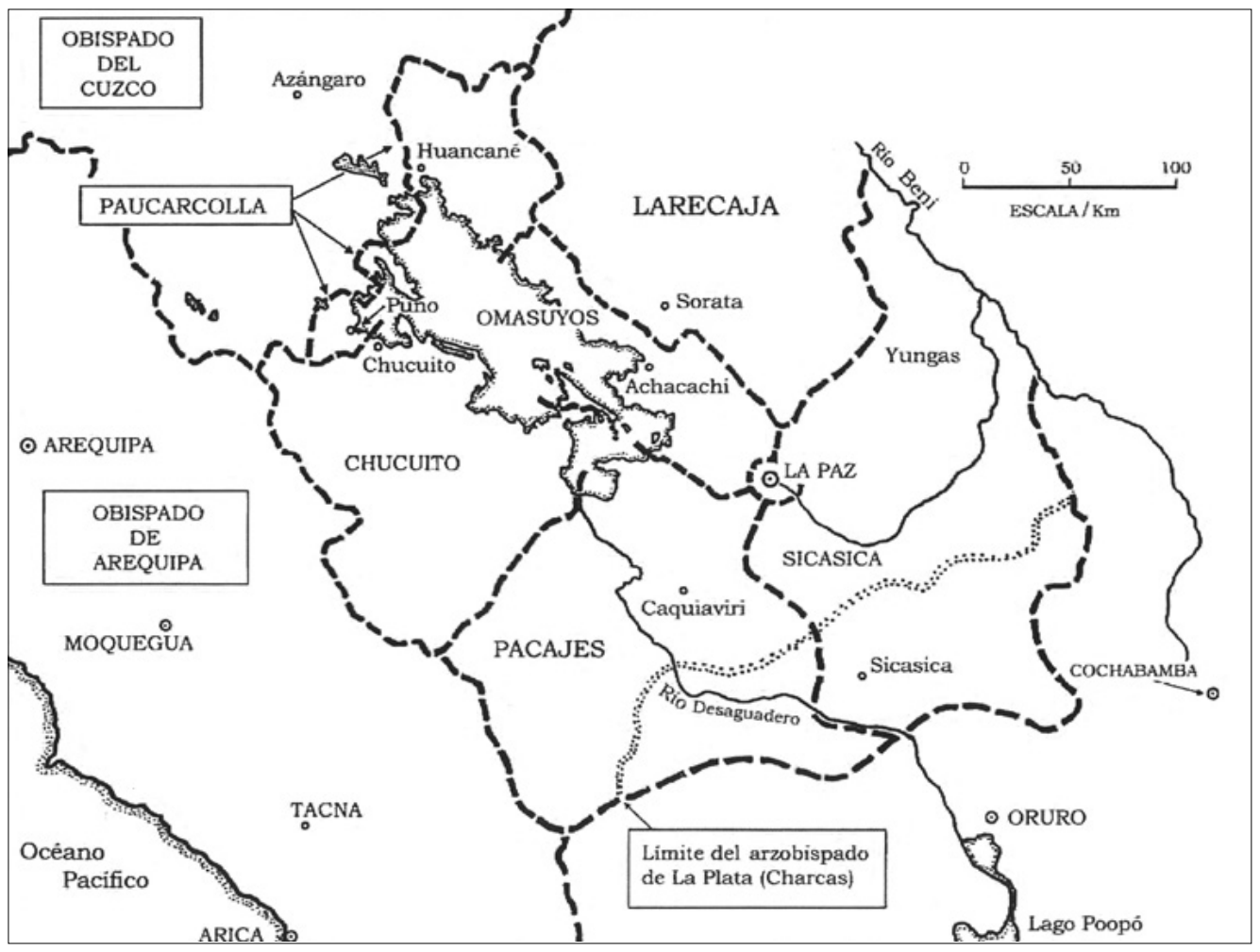

Figura 2. Provincias del Obispado de La Paz (intervenido a partir de Domínguez Faura 2010: 319). 
en vínculos económicos. En efecto, los factores personales y relacionales se retroalimentaban, generando en no pocas oportunidades enconadas competencias por obtener mejores posicionamientos en los distintos niveles de la administración diocesana (Ramos 1993; Taylor 1999 [1996]: 147-154; Hidalgo, Marsilli y Aguilar 2016).

Analizaremos estas consideraciones generales enfocando el caso particular del licenciado Pedro Vallejo de Velasco (Morrone 2013a: 46-48). El entrecruzamiento de su presentación ante el Consejo de Indias, solicitando prebendas y canonjías en las diócesis de Lima, Charcas o La Paz, con un conjunto de escrituras públicas protocolizadas en esta última ciudad nos permitió reconstruir el desarrollo, casi en paralelo, tanto de su carrera como cura a cargo de varias doctrinas como de los vínculos mercantiles establecidos con notables personalidades del escenario paceño.

A inicios de la década de 1630, el licenciado Vallejo de Velasco era cura del pueblo de Santa Bárbara de Caquingora y vicario y comisario de la Santa Cruzada del corregimiento de Pacajes. Por dos escrituras públicas de 1630 y 1631 sabemos que resultó beneficiado en el remate de la estancia ganadera de Poma Amaya (situada a mitad de camino entre La Paz y Viacha) por 1162 pesos y 1 tomín corrientes, que luego vendería al doctor don Pedro de las Cuentas Valverde, arcediano de la catedral de La Paz. ${ }^{8}$ En 1631, la muerte del segundo obispo de La Paz, don Pedro de Valencia, llevó al arcediano Cuentas Valverde a ejercer la gobernación del obispado durante el período de sede vacante. Junto a los miembros del cabildo catedralicio, en febrero de 1633, el arcediano designó a Vallejo de Velasco como visitador general y juez eclesiástico del obispado, ubicándolo en una posición de mayor jerarquía dentro del elenco de curas doctrineros. Entre las funciones asociadas al cargo, señalemos el control sobre el quehacer de los curas bajo su jurisdicción, es decir, la correcta administración de los sacramentos, el abastecimiento y mantenimiento edilicio de las iglesias y la confección de los registros parroquiales (libros de bautismos, matrimonios y defunciones). Asimismo, se le ordenaba

exsamine a los dichos curas beneficiados y clerigos ansi en la lengua de los naturales como en las materias morales, casos de conciencia y sacramentos y en el dezir misa y ceremonia della [...] = Y las de ydo-

8 ALP RE C21 L54, ff. 315v-318v y 640r-641v: Juan López Mexía. latrias supersticiones y echizeros aprehenda su conocimiento en cuyo particular procedera en la forma que esta dispuesto = procurando saver si los dichos curas an guardado y observado las cedulas de $\mathrm{Su}$ Magestad ynsertas en sus titulos.

Desde su cargo como visitador general, Vallejo de Velasco se convertía en lugarteniente directo de la autoridad diocesana para la regulación de la actividad religiosa en el obispado. En paralelo, operaría en la plaza mercantil paceña, fungiendo indistintamente como acreedor, fiador, cobrador, otorgante y apoderado. Veamos algunos ejemplos. En abril de 1633, el capitán don Joseph Márquez de Mansilla, antiguo corregidor de Pacajes, se obligó a devolver a Vallejo de Velasco 1598 pesos y 6 reales corrientes que aún le debía luego de ajustar sus cuentas. ${ }^{10}$ En febrero de 1634 , el cura ofició como fiador de don Pedro de Torres y Figueroa y doña Gerónima de Villegas por 300 pesos corrientes que ambos esposos debían al mercader Bartolomé Ramos, proveedor de mercaderías de Castilla para su tienda en la ciudad; asimismo, y como apoderado de los hermanos Francisco y Gaspar de la Fuente Vallezar, negoció con Felipe de Bolívar, apoderado a su vez de Pedro Felipe de Guadalupe (ambos residentes en Potosí), el pago de una deuda de 12.426 pesos corrientes en favor de los otorgantes. ${ }^{11}$ Luego, en julio de 1635 recibió un poder del mercader Antonio Pérez para vender en su nombre alrededor de 500 llamas "que se hallaren en poder de Christoval Fernandez que los tiene a su cargo". A los pocos días, y ante la noticia de la muerte de su padre, acaecida en la provincia de Parinachochas, otorgó poder a Juan Guerra de Pedraza, quien partía para esa jurisdicción, para recibir de los albaceas los bienes que le correspondieran por herencia. ${ }^{12}$

La retroalimentación entre sus contactos con el capítulo catedralicio y sus relaciones con importantes mercaderes paceños redundó en un fuerte posicionamiento político del licenciado Vallejo de Velasco en el escenario local. En este contexto entendemos el pleito que, en 1636, trabó contra el licenciado Antonio de Arisaga, cura de Ayo Ayo (corregimiento de Sicasica), por 3000 pesos que éste le debía. Para saldar la deuda, Arisaga cedió a Vallejo de Velasco el sínodo que, a su vez, le debía desde 1630 el licenciado Hernando

9 Archivo General de Indias (AGI), Charcas 92, N. 14, ff. 15v-16r. 10 ALP RE C23 L37, ff. 808r-808v: Juan López Mexía.

11 ALP RE C24 L38-1, ff. 91r-92v y 10or-102v: Juan López Mexía. 12 ALP RE C25 L41, ff. 411v-413v: Pedro de Manzaneda. 
Bermúdez, cura de La Magdalena de Yunguyo (gobernación de Chucuito).13 Vemos aquí cómo los sínodos podían emplearse para saldar deudas, contraídas generalmente en operaciones mercantiles. Verificamos, de este modo, que la cesión de deudas a través de cartas de pago y otorgamiento de poderes (para operaciones de compraventa, por ejemplo) constituía un importante mecanismo de circulación de obligaciones en una plaza altamente desmonetizada (Martínez López-Cano 2001: 45-88).

En 1634, el ascenso a la sede episcopal del obispo Vega implicó otro empuje en la ascendente carrera del cura de Caquingora. En junio de 1636, luego de finalizado el proceso de visita correspondiente, el obispo nombró a Vallejo de Velasco como predicador del obispado. ${ }^{14}$ Con este respaldo, en marzo de 1638 registramos su primer intento por trascender más allá de su doctrina: otorgó a don Juan de la Serna Haro de Vega, quien partía para Madrid, un poder para solicitar ante el Rey y al Consejo de Indias la asignación en merced de dignidades, prebendas y/o canonjías en el cabildo eclesiástico, como recompensa a los méritos y servicios brindados por sus antepasados. ${ }^{15}$ Expectante de respuestas favorables a su intento por ingresar al cabildo eclesiástico, Vallejo de Velasco continuó operando como articulador de una red de vínculos personales que crecía cada vez más. Su experiencia como visitador general del obispado y su posición como vicario, comisario de la Santa Cruzada del corregimiento y predicador general lo convirtieron en un referente para otros religiosos de la región. En efecto, en octubre de 1638 fungió como intermediario entre el bachiller Andrés García de Velasco, cura de Santiago de Machaca (corregimiento de Pacajes), y el licenciado Pedro de Molina, cura de la catedral y secretario del obispo, con motivo de saldar una deuda de 1000 pesos corrientes que el primero había contraído con el segundo. ${ }^{16}$ Por otra parte, a principios de 1639, Vallejo de Velasco gestionó un cambio de jurisdicción, contando con el aval de don Juan de Lizarazu, presidente de la Audiencia de Charcas, quien en virtud del patronato real solicitó al obispo de La Paz la designación de Vallejo de Velasco como cura del pueblo de San Pedro de

13 ALP Expedientes Coloniales (EC), C11 E7.

14 AGI Charcas 92, N. 14, ff. 17v-18r.

15 ALP RE C27 L44, ff. 192r-192v: Pedro de Manzaneda. Cf. Coello de la Rosa 2011.

16 ALP RE C27 L44, ff. 607r-607v: Pedro de Manzaneda.
Moho (corregimiento de Paucarcolla) tras la muerte del bachiller Nicolás Lucero. Casi en simultáneo, el obispo Vega fue promovido a la sede arzobispal de México; reconociendo que, debido a su inminente partida "no podremos visitar por nuestra persona tercera vez las provincias de Paucarcolla y de Omasuyo", Vega nombró a Vallejo de Velasco como visitador general y juez eclesiástico, con la advertencia de "que si en la doctrina de Ancoraimes de la dicha provincia de Omasuyos resultare alguna cosa contra el cura se abstenga de ser juez en ella por ser su hermano para que corra por otra mano el conocimiento". Ya partido el obispo, el gobierno en sede vacante recayó en el entonces deán don Pedro de las Cuentas Valverde, quien nuevamente propulsó la carrera de Vallejo de Velasco invistiéndolo con los cargos de comisario de la Santa Cruzada, juez eclesiástico y vicario general de todo el obispado. ${ }^{17}$

Llegados a este punto, resulta clara la densidad de la red que, a lo largo de la década de 1630, logró tejer Vallejo de Velasco. Su estrecho vínculo con el capítulo catedralicio y con la corporación de mercaderes se consolidó durante el obispado de don Feliciano de Vega, quien lo promovió a cargos que le permitieron exceder el escenario local del pueblo de Caquingora y proyectar su influencia hacia toda la diócesis.

Para 1640, la Audiencia de Charcas aprobaría una nueva promoción: Vallejo de Velasco permutó el curato de Moho por el de Caquiaviri hanansaya (corregimiento de Pacajes) con el licenciado Martín de Ypeñarreta. Fundado como pueblo de reducción en época toledana como Concepción de la Nueva Toledo, Caquiaviri era la sede de la vicaría y la residencia del corregidor de Pacajes. Para las primeras décadas del siglo XVII, los caciques de Caquiaviri eran los principales articuladores de la tributación y ocupaban cargos de gran relevancia en la organización de la mita potosina. A su vez, era uno de los pueblos más densamente poblados y con más riquezas ganaderas de la región, incluso a pesar de la caída demográfica registrada para esa época (Choque Canqui 1998; Morrone 2013b). Para un sacerdote en pleno ascenso, la designación como cura de una de las dos doctrinas del pueblo podía ser vista como una prenda valiosa en términos políticos, aunque el sínodo fuera un tanto menor que el anterior. El auto de nombramiento de Vallejo de Velasco como cura de la parcialidad hanansaya incluía un

17 AGI Charcas 92, N. 14, ff. 18r-25r. 
pormenorizado detalle de sus obligaciones; no solo debería garantizar que los indígenas asistieran a misa y observaran la fe católica.

Yotrosi le nombro por cura de los españoles y mestizos mulatos negros y zambaygos que vivieren y residieren en la dicha doctrina de Caquiaviri y sus anejos como dicho es a los quales administrara los dichos Santos Sacramentos y en el de la penitencia les absuelva de todos sus pecados guardando en los casos reservados lo dispuesto por derecho y Sacros Concilios Tridentino y Limense del año de 583 y constituciones y signodales deste obispado... ${ }^{18}$

\section{Así, el día de Nochebuena de 1640, Vallejo de Velasco}

tomo posesion del dicho su beneficio en la yglesia donde abrio la puerta y en el altar mayor estendio los corporales sobretarde en señal de la dicha posesion todo ello con asistencia del capitan don Geronimo Vazquez de Herrera corregidor y justicia mayor desta dicha provincia y del Bachiller don Christoval Mesia Poblete beneficiado deste dicho pueblo de la parcialidad de hurinsya... ${ }^{19}$

El meteórico ascenso de Vallejo de Velasco llegó a un punto culmine en 1641, cuando, en primer lugar, el presidente de la Audiencia de Charcas elevó un informe al rey sobre la calidad y los méritos del sacerdote, y en segundo lugar, el deán y cabildo eclesiástico de La Paz en sede vacante renovaron su designación como visitador general del obispado. ${ }^{20}$ Este incremento en el capital político acumulado por Vallejo de Velasco presentó un fuerte correlato con un aumento en la escala de las operaciones mercantiles y con un ensanchamiento de las redes de influencia. En noviembre de 1642 lo registramos como fiador de Francisco de Carvajal, hacendado en el valle de Luribay (yungas orientales de la Paz), en una escritura de censo en favor de los indígenas del pueblo de Achacachi (corregimiento de Omasuyos) por 200 pesos de renta anual por 2800 pesos de principal, "ynpuestos sobre las hasiendas de Matara en el dicho valle que fueron del padre Gabriel de Silva presbitero y otras del susodicho que tenia en el de Taguapalca y en esta çiudad". ${ }^{21}$ En marzo del año siguiente labró una escritura de concierto con Juan Ramírez Tenorio, albacea y tenedor de bienes del genovés Juan

18 AGI Charcas 92, N. 14, ff. 10v-11r.

19 AGI Charcas 92, N. 14, f. 11v.

20 AGI Charcas 92, N. 14, s/f. 6r-6v y ff. 25r-27v.

21 ALP RE C30 L49, ff. 548r-548v: Pedro de Manzaneda.
Baptista Vivaldo y tutor y curador de sus hijas menores, por el cual se establecía que Manuel Camargo Xironda, regidor y procurador general de La Paz, y el maestre de campo don Joseph Márquez de Mansilla viajarían a Génova de parte de Vallejo de Velasco para cobrar 3000 ducados que les correspondían a las hijas de Vivaldo. Para asegurar tamaña empresa, el cura puso en garantía sus bienes y "las hasiendas de Achumani que tiene por propias en terminos del valle del batan que tiene pagadas y satisfechas a sus ermanos". ${ }^{22}$ Cuatro días después, aceptaba junto al bachiller Pedro Gómez de Cenabria ser apoderados cobradores del doctor don Pedro de las Cuentas Valverde, deán de la catedral. ${ }^{23}$

Tal como lo había hecho cinco años atrás, en marzo de 1643 Vallejo de Velasco volvió a solicitar al Rey y al Consejo de Indias se le otorguen mercedes, dignidades y canonjías, a través de un poder entregado a sus operadores Camargo Gironda y Márquez de Mansilla; el primero de ellos efectivamente viajaría a Madrid a principios del año siguiente. ${ }^{24}$ Entre tanto, y como apoderado del capitán don Gerónimo de Quintana y Benavides, Vallejo de Velasco saldaría una deuda de 3780 pesos ensayados con las Cajas Reales de La $\mathrm{Paz}$, "las quales son por el precio y valor de sesenta quintales de asogue neto que yo el dicho principal reçevi del alamsen real desta real caxa por mi y el dicho mi parte para el beneficio de los metales que tenemos en las minas de Sasari". Contaba para ello con las fianzas del sargento mayor don Juan de Gauna y Guevara, corregidor de Paucarcolla, y del capitán Francisco de Benavides Maldonado, corregidor de Omasuyos. Para asegurar la obligación, Vallejo de Velasco hipotecó "las casas principales que tengo en esta çiudad en la calle de San Agustin linda con las de doña Marina Dalvares y otros linderos las hasiendas de Achumani el rio abaxo desta çiudad". ${ }^{25}$ Nuevamente observamos aquí el apoyo de dos altos funcionarios del poder local, que junto a su creciente patrimonio inmueble confluyeron para sostener, en este caso, una explotación minera en el corregimiento de Sicasica, donde Vallejo de Velasco también era hacendado. De hecho, fue beneficiario del remate de diezmos de los pueblos de San Juan de Suri y Santiago de Circuata por un

22 ALP RE C31 L50, ff. 112r-114r: Pedro de Manzaneda.

23 ALP RE C31 L5O, ff. 122r-122v: Pedro de Manzaneda.

24 AGI Charcas 92, N. 14, s/f. 3r-5r.

25 ALP RE C31 L50, ff. 154r-156r: Pedro de Manzaneda. El asiento de minas de San Pedro de Sasari se ubicaba a pocos kilómetros al este del pueblo de Sicasica. 
total de 606 pesos y 3 tomines corrientes, que debería pagar a la catedral de La Paz y su mesa capitular. ${ }^{26}$ Ese mismo año también fue apoderado cobrador del licenciado Blas de Linares Cuadrado, racionero de la catedral; del licenciado Nicolás Calderón de Ocampo, cura de Combaya (corregimiento de Larecaja) para el pago de 1578 pesos corrientes que éste debía en un pleito contra el bachiller Bernardo de Sotomayor; y del licenciado Francisco de Belmonte, cura de San Pedro de Tiwanaku, para la cobranza de su sínodo. ${ }^{27}$ Como ya venimos observando, los poderes también abonaban a la condensación de las redes personales en sentido inverso: en julio de 1643, Vallejo de Velasco otorgó un poder junto a don Baltasar Ramírez de Vargas, comisario del Santo Oficio, cura del pueblo de Laja y vicario de Omasuyos, el bachiller Christoval de Escalante, cura de Sapahaqui y vicario de Sicasica, don Juan de Fuentes, rector de la catedral, el bachiller Luis de Torres Restrojo, cura de las parroquias de Santa Bárbara y San Sebastián de La Paz, y Bartolomé de Medina, en nombre de su hermano el bachiller Diego de Medina, cura de San Pedro de Chucuito y vicario de la provincia, a Juan de Valdés, procurador de la ciudad de La Plata, para que los represente en pleitos. ${ }^{28}$

Entre sus obligaciones como cura doctrinero, como referente de gran influencia en el obispado y como operador de una densa red clientelar, Vallejo de Velasco recibió, en septiembre de ese año, una notificación del escribano real Gaspar Falgas. En ella, el virrey don Pedro de Toledo y Leyva, marqués de Mancera, ordenaba a todos los curas doctrineros del virreinato la confección de un padrón donde consignaran detalladamente la cantidad de indígenas naturales y de forasteros que residían en cada pueblo, con el objetivo de concretar, finalmente, el nuevo repartimiento general de los mitayos de Potosí, que desde inicios de la década anterior había quedado pendiente (Cole 1985: 77-87). Para cumplir la orden virreinal, Vallejo de Velasco reunió a los cuatro caciques principales de Caquiaviri para que dieran cuenta de la situación. Entre antiguos padrones, registros parroquiales y testimonios orales, el cura elaboró los listados solicitados. La visita arrojó un total de 664 "indios naturales", menos de la mitad de los 1509 registrados en la visita toledana.

26 ALP RE C31 L5o, ff. 435r-435v: Pedro de Manzaneda.

27 ALP RE C31 L5O, ff. 157v-158r, 314r y 432r-432v: Pedro de Manzaneda.

28 ALP RE C31 L50, ff. 301r-301v. Pedro de Manzaneda.
Esta merma en la masa tributaria impactaba directamente en la disposición de la mano de obra mitaya. Para dar cuenta de la situación, Vallejo de Velasco redactó un informe de nueve capítulos, donde adjudicaba la caída de la población tributaria al ausentismo indígena, del que los caciques eran principales responsables. ${ }^{29}$

Suspendemos aquí el relato de este episodio puesto que su conclusión será abordada en el apartado siguiente. Para dar un cierre a la carrera del licenciado Pedro Vallejo de Velas$\mathrm{co}$, resta agregar una nueva faceta, que recorrió en los últimos años de su vida. Entre mayo de 1648 y julio de 1649 actuó como albacea testamentario y tenedor de bienes del licenciado Cosme de Guzmán Chirino, cura de Calacoto, en virtud de lo cual vendió a Domingo de Montealegre "unas casas de vivienda en esta çiudad en la calle que va a la piedra de la Paçiençia alindan con casas que fueron de Alonso de Lovera y las de doña Juana de Gamboa por arriva y por un lado casas de Juan Baptista Vendeli" por 1500 pesos corrientes; y al capitán Juan de Valencia, "una guerta y tierras quel dicho difunto dexo en el valle de Mecapaca nombrada San Yldefonso linda con la hasienda que fue del governador Francisco de Barrasa y despues de doña Mariana de Ysasaga por una parte y por la otra con el rio y con la quebrada de Quielcata con las casas que tiene y todo lo que le pertenece" por 50 pesos corrientes de censo por 1000 pesos de principal. Asimismo, Vallejo de Velasco otorgó un poder a su allegado doctor Cuentas Valverde (a la sazón, deán de la iglesia metropolitana de Lima) para cobrar los 1500 pesos corrientes que Guzmán Chirino había remitido a Diego de Medrano, teniente de correo mayor de Lima, para realizar negocios que éste nunca concretó. ${ }^{30}$

29 AGN IX, 20-4-4. Para 1645, los caciques de Caquiaviri eran don Juan Colque Guanca y don Francisco Choque Mamani (hanansaya), y don Esteban Oliveros y don Antonio Colque Guanca (hurinsaya). En líneas generales, existe un consenso en la historiografía al considerar que la caída demográfica operada en el sur andino entre las últimas décadas del siglo XVI y la primera mitad del siglo XVII obedeció tanto a la difusión de epidemias y malas cosechas como a la intensificación de las migraciones de grandes contingentes de mitayos (y sus familias) hacia corregimientos vallunos, estancias de españoles y/o núcleos urbanos. Este "ausentismo indígena" revestía un carácter "táctico anti-fiscal”, cuyo objetivo era eludir las obligaciones de la mita potosina (Saignes 1984).

30 ALP RE C33 L51a, ff. 137r-139v, 192 r-193v y 313r-314r: Pedro de Manzaneda. El licenciado Guzmán Chirino era hijo de don Cosme de Guzmán y de doña Ana de Chirino Pernia, notables veci- 
El licenciado Pedro Vallejo de Velasco falleció a principios de $1654 .^{31}$ Durante casi veinticinco años fue un referente central en la vida religiosa, económica y política del escenario paceño. A pesar de que su carrera político-eclesiástica fue en ascenso, no logró acceder al cabildo catedralicio de La Paz, objetivo por el que apeló ante los más altos estrados de la administración española en 1638 y 1643 . De todos modos, su prominente posición (o tal vez su interés por demostrar su eficacia, saber y experiencia) se tradujo en palabra autorizada para la redacción de un balance general sobre la situación de los pueblos de la región lacustre al promediar el siglo XVII y del lugar que en ella cupo a los caciques, hacia quienes dirigiremos ahora el foco de nuestro análisis.

\section{* Los caciques en el armado del poder local}

En este apartado ensayamos una caracterización sobre algunas modalidades que adoptaron las relaciones entre los curas doctrineros y los caciques de la región estudiada. Entendemos que este esfuerzo constituye una forma práctica para conceptualizar dichos vínculos y para diseñar posibles líneas de análisis, ya sea en términos situacionales (sobre el mismo actor o episodio) o comparativos.

Nuestro recorrido se inicia en el pueblo de Acora (gobernación de Chucuito) a inicios del siglo XVII. En marzo de 1603, don Juan Poma Catari, cacique principal de la parcialidad hurinsaya del pueblo y "governador de los naturales de la provincia" reconfirmó a Martín Cutipa, tributario del ayllu Guancollo del vecino pueblo de Juli, para que sirviera a los religiosos del colegio jesuita de La Paz, "por constarme que a muchos años que a estado en el dicho servicio de los dichos padres y ellos tener cuidado de pagar su tasa a su pueblo y alimentalle en todo su bestir y sustento". Con el objetivo de congraciarse con los padres jesuitas, y en virtud de su cargo como autoridad a escala provincial, Poma Catari no solo dispuso de la fuerza de trabajo de un tributario de

nos paceños y miembros de la familia encomendera de Guarina hurinsaya (Morrone 2012). Es probable que los licenciados Vallejo de Velasco y Guzmán Chirino hayan entablado vínculos durante sus respectivos oficios al frente de las doctrinas de Calacoto y Caquingora, pueblos de reducción fundados en época toledana a partir del mismo repartimiento pretoledano (Rivera Cusicanqui y Platt 1978).

31 ALP RE C34 L52-1, ff. 322r-322v: Pedro de Manzaneda. otro pueblo de reducción, sino que también exhortó a los propios caciques de Juli para que "no le ynquieten ni perturben en cosa alguna de lo suso referido so pena de que seran castigados". ${ }^{2}$ Dado que Poma Catari estaba intensamente enemistado con otros caciques de la provincia de Chucuito por su participación en el entero de la mita de Potosí, entendemos este gesto como un intento por reafirmar su posición política en el escenario local. ${ }^{33}$

Los vínculos que Poma Catari entablara con los jesuitas de La Paz parecen haberse extendido hacia otras órdenes religiosas. Por una escritura de 1632 sabemos que el ya difunto cacique había estado casado con doña Beatriz Quispe Molle, hija legítima del hermano franciscano Pedro de San Francisco, quien en agosto de ese año le donó "todos mis ganados vacunos y obexunos ansi de Castilla como de la tierra que tengo y me perteneçen". ${ }^{34}$ Más de veinte años después, en diciembre de 1659 los religiosos del convento de Santo Domingo de la ciudad aceptarían la fundación de una capellanía por parte de don Juan Vaca Dávila, albacea testamentario de don Pedro Poma Catari (hijo y sucesor de don Juan al frente del cacicazgo de Acora hurinsaya) y en nombre de su viuda, doña Florencia Ramos Choque. El objetivo de don Pedro al establecer la capellanía fue garantizar ocho misas anuales rezadas por su alma, la de su esposa y las de sus antepasados,

dotadas a tres pesos y un real la limosna de cada una que montan veintiçinco pesos de renta por quinientos de prinçipal situados sobre las hasiendas de panllevar de Moyoguaia en la jurisdiçion del pueblo de Quiabaia que fue de la dicha doña Florençia que oy posee don Juan Vaca Davila a quien nombro por su albacea.35

32 ALP EC C 3 E19.

33 Cf. el nombramiento de don Juan Poma Catari como "juez reducidor" (Lima, 5 de enero de 1601) en AGI Lima 34, citado en Espinoza Soriano 1960: 285-286. Sobre el conflicto entre los caciques de la Provincia de Chucuito, cf. Glave 2010. Sobre los jesuitas en Chucuito, cf. Meiklejohn 1988: 28-62; Finegan 1999: 17-42; Salles 2001; Coello de la Rosa 2007 y González 2014.

34 ALP RE C23 L37, ff. 436r-438v: Juan López Mexia. Muy probablemente, doña Beatriz fuera hija mestiza del religioso.

35 ALP RE C27 L55, s/f: Pedro de Manzaneda. Establecimos la filiación entre don Pedro y don Juan Poma Catari a partir de ABNB Min 124-1, ff. 552r-552v, transcripto en Medinacelli e Inch 2010: 308. Asimismo, resulta sugerente que el hijo de don Juan llevara el mismo nombre de pila que su abuelo materno, el religioso franciscano. 
Las relaciones entre la familia cacical de Acora hurinsaya y ciertos miembros del clero regular de La Paz pudieron haberse iniciado, según entendemos, como una estrategia política desplegada por don Juan Poma Catari en una coyuntura crítica de redefinición de las relaciones de poder a escala local, pero también darían cuenta del despliegue de cierto habitus cacical, exigido por las autoridades coloniales, que implicaba la necesidad de mostrarse como "buenos cristianos", en tanto mecanismo de consolidación de su posición intermediaria. ${ }^{36}$

Nos trasladamos al sur del lago para relatar nuestro segundo episodio. Entre 1628 y 1630 tuvo lugar un enconado pleito entre los caciques del pueblo de Laja (corregimiento de Omasuyos) contra su pares del pueblo de Guaqui (corregimiento de Pacajes) por la tenencia de la estancia agroganadera de Cantapa, ubicada entre ambos pueblos. ${ }^{37}$ Aduciendo derechos de posesión desde "tiempo ynmemorial", don Baltasar Guamani, cacique de Guaqui hurinsaya, y don Fernando Quino y don Juan Bautista Vilca Laura, caciques principales de Laja, incursionaron en la memoria propia y de sus testigos para sustentar sus reclamos. Los caciques rivales remitían tanto al "tiempo del Ynga" como a la visita toledana como hitos claves en la memoria colectiva, acusándose mutuamente de usurpar la estancia, explotar sus recursos y pretender ejercer jurisdicción sobre sus pobladores.

Además de este argumento "histórico", don Baltasar Guamani aducía que los pastores destacados en Cantapa eran doctrinados por uno de los dos curas del pueblo. Para justificar este alegato, presentó como prueba una petición efectuada en enero de 1600 por él y por don Felipe Chuy Callisaya, cacique de hanansaya, a través del fiscal del pueblo, don Alonso Mamani, ante don Alonso Ramírez de Vergara, obispo de La Plata. En la misma, los caciques referían

que por la misericordia de Dios en el dicho pueblo ay christiandady doctrina y cura como subjetos al dicho pueblo an sido y son doctrinados y se les an administrado los santos sacramentos por los curas que en el an sido y son ansi por la dicha razon como porque todos los mas yndios que en la dicha estancia y anexos della residen naturales

36 Sobre los "caciques cristianos" de la región estudiada, cf. Gisbert 1980: 92-99; y Choque Canqui 2003: 125-164.

37 ABNB EC 1630-2. Cf. Choque Canqui 1993: 20, 56-57, 64-65; Pärssinen 2005: 237-239; Morrone 2015. del dicho pueblo de Guaqui como por que alli con mas comodidad pueden acudir a lo susodicho y a los divinos oficios. $3^{38}$

Por el contrario, los curas de Laja no podían doctrinar a los pastores de Cantapa por su lejanía y porque "en el camino ay rios e pasos peligrosos en tiempo de aguas donde aunque quisiesen no podrian acudir". ${ }^{39}$ Asimismo, la petición refería al mal proceder del padre Miguel Merino, cura de Laja, quien se entrometió en la estancia e incluso tomó por la fuerza a varios pastores, todo ello a pesar de que, desde 1584 , existieran específicos mandamientos privativos ordenados por el obispo.

Para sustentar su causa, en enero de 1629 los caciques de Guaqui presentaron catorce testigos. Entre ellos, se encontraban el licenciado Gómez de Rivera, canónigo de la catedral de La Paz, y Juan Martel de Narváez. Como cura de Santiago de Machaca a principios de siglo, Rivera avaló las pretensiones de los caciques de Guaqui, aclarando en su testimonio que los curas de ese pueblo también administraban los sacramentos a muchos españoles. Lo mismo refirió Narváez, quien recordaba la labor de don Fernando de Padilla, antiguo cura de Guaqui. Finalmente, don Martín Calle, principal del ayllu Achaca de Tiwanaku hurinsaya, agregó que los pastores de Cantapa habían fundado allí una capilla y una cofradía. ${ }^{40}$

Pero los caciques de Laja no se amilanaron: también presentaron sus testigos. Don Adrián Aroquipa, del ayllu Maacollana de Pucarani hanansaya, adjudicó a los pobladores de Laja la construcción y mantenimiento de la capilla, instaurada bajo la advocación de San Pedro, "donde los curas del dicho pueblo de Laxa ban y an ydo siempre a dezir misa a sus yndios y hecho sus fiestas y nombrado alferez en que este testigo se a hallado a ellas a cantar como maestro de capilla de este pueblo". El testimonio de Aroquipa era clave para los caciques de Laja, ya que afirmaba taxativamente "que pidiendole los caciques e yndios de el dicho pueblo de Guaqui a su cura que fuese a dezir misa a las dichas estancia y tierras de Cantapa les respondia que quando aca hemos

38 ABNB EC 1630-2, ff. 9r-9v.

39 ABNB EC 1630-2, f. 9v. Se trata de los ríos Pallina, Catari y Guaquira, que corren en sentido SE-NO hasta desembocar en el lago. 40 ABNB EC 1630-2, ff. 70r-72r, 75r-77v y 91v. 
ydo a dezir misa a esas tierras". ${ }^{41}$ Por su parte, los españoles Francisco de Salinas y Juan de Solórzano refirieron que en reiteradas oportunidades habían visto a los curas de Laja (particularmente al licenciado Nicolás Calderón) ir y venir de la capilla de San Pedro de Cantapa para decir misa, mientras que Lorenzo Coro (yanacona natural de La Paz) y Sebastián Mamani (principal del ayllu Omcasoca de Viacha hurinsaya) repararon en "que los dichos curas deste pueblo de Laxa an ydo siempre a selebrar la fiesta de San Pedro porque tienen su capilla desta adbocaçion y nombran alferes y haçen su fiesta con mucha solenidad como en tierras suyas conosidas".42

La participación de los curas doctrineros en el sostenimiento de la misa dominical, la administración de los sacramentos y la organización de las fiestas patronales de los habitantes de Cantapa fue un recurso que los caciques de ambos pueblos pusieron en juego a la hora de esgrimir sus alegatos. Demostrar que el cura del propio pueblo también estaba a cargo de la vida religiosa de los pocos feligreses que habitaban en la estancia implicaba, en esta construcción argumental, su dependencia jurisdiccional.

Las justicias coloniales constituyeron, como ya es sabido y pudimos apreciar en el caso anterior, arenas de conflicto donde curas y caciques interactuaron intensamente. Así como los primeros podían colaborar con el sustento de las causas de los segundos ante los estrados coloniales, también los asistían de formas más directas en situaciones acuciantes, cuyos indicios registramos en las escrituras públicas. Tras varias décadas al frente de las doctrinas de Ayo Ayo, Caquiaviri y Viacha, y como principal operador de los negocios inmuebles (urbanos y rurales) de sus hermanos, don Pedro Díaz de Pisa y Saavedra testó ante el escribano Pedro de Manzaneda el 17 de julio de $1630 .{ }^{43}$ El religioso mandó pagar a sus albaceas 100 pesos corrientes a las igle-

41 ABNB EC 1630-2, ff. $182 \mathrm{r}-185$ r.

42 ABNB EC 1630-2, ff. 185r-198r. Sobre el licenciado Calderón, cura de Laja, sabemos que, en noviembre de 1630 (es decir, durante el transcurso del pleito), recibió en donación "un citio destançia para ganado de Castilla” lindero de la estancia de Cantapa, de parte de don Agustín de Espinosa y Céspedes, notable vecino paceño y encomendero en segunda vida de Laja. ALP RE C20 L33, ff. 656r-656v: Pedro de Manzaneda.

43 ALP RE C20 L33, fs. 449r-458v: Pedro de Manzaneda. Cf. Morrone 2013a: 43-46. sias donde había oficiado como doctrinero, aclarando que debía otros 900 pesos a los caciques de Viacha por los servicios personales que durante seis años le habían brindado los tributarios de ese pueblo, de los cuales debían descontarse 300 pesos que el cura ya había adelantado para refaccionar la iglesia. Tal como vimos para el caso de la familia cacical de Acora, los caciques de Viacha también buscaban posicionarse como "buenos cristianos", contribuyendo a mejorar las condiciones edilicias de la iglesia. Finalmente, el cura también descontaba 60 pesos de la fianza pagada para liberar de prisión al cacique don Pedro Calisaya. Más allá de la intención del cura y de los propios feligreses por posicionar sus "buenas obras" ante la fe pública, vemos que el cacique de Viacha debió contar con el auxilio del cura para poder salir de la cárcel donde estaba preso por haberse retrasado en el pago de las cargas coloniales.

Pero el accionar de los curas no siempre operó en favor de los caciques. Así lo revela una escritura que, en noviembre de 1632, labrara don Lorenzo Condori, cacique principal de Caquiaviri, en favor de don Luis de Barrasa y Cárdenas, cura del pueblo, donde reconocía haberse dejado llevar por malas influencias para levantar quejas en contra del sacerdote ante las altas jerarquías diocesanas. Miembro de una notable familia paceña y descendiente de los primeros encomenderos de Guaqui, desde principios de siglo don Luis había ocupado varios curatos rurales en torno al lago (Paucarcolla, Ayo Ayo y Viacha) y, junto a su hermano el general don Antonio de Barrasa y Cárdenas, asimismo vecino notable, estaban estrechamente relacionados con la élite arequipeña a partir del comercio del vino de los valles paceños de Caracato, tanto en Arequipa como en el puerto de San Marcos de Arica y en Potosí (Assadourian 1983: 18; Choque Canqui 1993: 125-157).44 La proyección política y mercantil de los hermanos Barrasa y Cárdenas muy probablemente dejara en una complicada posición al cacique de Caquiaviri, quien no tardó en aclarar los motivos de su descontento. Al parecer, el sacerdote habría criticado las habilidades del cacique para asegurar la observancia religiosa entre sus feligreses, mientras que éste habría elevado la denuncia a instancias de terceras personas enemistadas con el cura. ${ }^{45}$ Como solución de compromiso, don Lorenzo Condori re-

44 Sobre don Antonio de Barrasa y Cárdenas, cf. López Beltrán 1998: 53-57; y Morrone 2012.

45 ALP RE C22 L36, fs. 528r-529r: Pedro de Manzaneda. 
tiró los cargos presentados, muy probablemente en pos de mantener la concordia con el influyente sacerdote.

¿Cuán elásticos podían ser los vínculos entre un cura doctrinero y un cacique? En septiembre de 1638, el licenciado Rodrigo Niño de las Cuentas Valverde, cura de Jesús de Machaca, recibió la visita del licenciado Blas Moreno Hidalgo, cura y vicario de San Juan de Acora y comisario de la Inquisición, nombrado visitador general por el obispo Vega. Tras decir misa, inventariar los instrumentos del oficio religioso y evaluar la "ladinidad" de la feligresía, el visitador comisionó al cura para que exigiera a don Gabriel Fernández Guarachi, cacique del pueblo, la construcción de un sagrario y una lámpara de plata y la refacción de las puertas de la iglesia, ya que "donde esta un cacique tan rico y pueblo tan entero es mui grave culpa que no se haga todo lo susodicho siendo cosa esta ynportante al servicio de Nuestro Señor" ${ }^{46}$ Finalmente, el visitador recomendó enfáticamente:

Yten que por quanto algunos curas hacen ausencias de sus veneficios de que resultan los daños que la espiriencia nos muestra el señor visitador mandabay mando que ningun cura salga de su veneficio y feligresia mas de seis a siete leguas que pueden distar de unos veneficios a otros para poderse confesar lo qual se entienda en particular en las juntas de la mita de Potosi en el asiento de Topoco donde solo el cura de aquel partido y jurisdicion del territorio asistira por quanto conviene se eviten las ofensas de Nuestro Señor que en tales juntas se hacen con ocasión de decir ban con sus feligreses a los quales administrara con licencia de Su Ilustrisima o de dichos curas el que lo es de aquel distrito. ${ }^{47}$

La exhortación enfatizaba la necesidad de garantizar la presencia efectiva de los curas en la sede de su doctrina, evitando exceder las siete leguas en el cumplimiento de su oficio: deberían ser los curas del asiento de Topohoco, lugar de congregación de los mitayos en camino a Potosí, los encargados de evitar "las recurrentes ofensas de Nuestro Señor que en tales juntas se hacen". Ahora bien, estas recomendaciones del visitador, que buscaban reforzar el celo de los curas sobre reuniones y prácticas tildadas de "idolá-

46 Iglesia de Jesucristo de los Santos de los Últimos Días (IJSUD), Centro de Historia Familiar (CHF), Libro de Bautismos de Jesús de Machaca (LBJM), Microfilm 1278280, Ítem 7, ff. 311v-312r. Cf. Morrone 2010.

47 IJSUD-CHF. LBJM, ff. 312v-313r. tricas", contrastan con la escasa evidencia sobre campañas de "extirpación de idolatrías" en la región estudiada (Saignes 1984; Barnadas 1993). Sospechamos que, durante las décadas centrales del siglo XVII, las negociaciones entre el cura Niño de las Cuentas Valverde y el cacique Fernández Guarachi mantuvieron cierto statu quo en el entramado de los nudos del poder local, posibilitando tanto las obras de refacción para la iglesia y una mínima observancia cristiana como la reproducción (solapada) de ciertos cultos prehispánicos o temprano-coloniales (Mills 2004; Bouysse-Cassagne 2005; Hidalgo Lehuedé 2011). Abona esta hipótesis el hecho de que en las visitas eclesiásticas realizadas a posteriori no solo no se registraran quejas ante el visitador por eventuales abusos del cura doctrinero, sino que ni siquiera incluyeran informes cualitativos similares al de $1638 . .^{48}$ En cualquier caso, cabe la posibilidad de que otras fueran las motivaciones que expliquen el "mutuo entendimiento" entre el cacique y el cura. ¿Será que la notable influencia de Fernández Guarachi en la administración de la mita potosina lo convertía en un aliado estratégico?

Nuestro último episodio tiene como protagonista al tan mentado licenciado Pedro Vallejo de Velasco, cura de Caquiaviri en 1645 y autor de un informe sobre la crítica situación demográfica de la región. A la hora de ponderar la responsabilidad de los caciques frente al ausentismo de la mano de obra mitaya, Vallejo de Velasco no trepidó en imputarlos de "borrachos en general e yncapaces los mas", entre otros motivos porque "comen y beben lo que pueden y quando se hallan empeñados y acoçados de trabajo y obligaciones son los primeros que se ban" de los pueblos de reducción. Si bien el cura compartía la opinión generalizada en torno a que los caciques ocultaban tributarios, entendía que a esa altura era imposible "distribuyr tanta carga en tan pocos". En efecto, habida cuenta de que escaseaban los caciques que pudieran efectivamente concentrar los efectivos para la mita, Vallejo de Velasco sentenció: "si bien algunos caciques que tienen gobierno conserban sus pueblos pero son muy raros y finalmente conforme es el cacique asi esta cada pueblo". 49

48 Por ejemplo, en 1642, el visitador don Baltazar Ramírez de Vargas mencionaría, casi al pasar: "visto este libro de bautisados y hallo sus partidas como deven estar escritas". IJSUD-CHF.

LBJM, f. $277 \mathrm{v}$.

49 AGN IX, 20-4-4. 
A pesar del cariz negativo, displicente y desalentador de su discurso, el pronunciamiento de Vallejo de Velasco sobre los caciques nos devuelve un panorama en el que la diversidad situacional impedía generalizar una política uniforme. Desde el análisis historiográfico, existe un consenso en torno a las variedades y ambigüedades que presentaron las trayectorias de construcción del liderazgo étnico en los mundos andinos coloniales (Stern 1987). Similares consideraciones podríamos, pues, plantear a la hora de reconstruir las carreras político-eclesiásticas de los curas doctrineros y sus relaciones con las otras autoridades locales (caciques, corregidores)..$^{\circ}$

\section{* Consideraciones finales}

Nuestro trabajo buscó analizar la conformación de las redes locales del poder colonial y la actuación de sus principales operadores, haciendo foco en las doctrinas habilitadas en los pueblos de indios de los corregimientos adyacentes al lago Titicaca entre el último cuarto del siglo XVI y la primera mitad del siglo XVII. Tras caracterizar de manera general los derroteros del proceso de evangelización de la población nativa y contextualizar la organización territorial de la diócesis paceña, indagamos las carreras político-eclesiásticas de sus curas doctrineros (particularmente sobre uno de ellos, el licenciado Pedro Vallejo de Velasco) para llevar luego la mirada a los vínculos entre los sacerdotes y los caciques, argumentando que los nudos de poder local estaban atados en torno a las interacciones entre ellos operadas.

Los episodios aquí narrados dan cuenta de una gran variabilidad de escenas. Para la primera mitad del siglo XVII, verificamos las siguientes situaciones: una familia cacical con intensas relaciones con miembros del clero regular; curas interviniendo en pleitos entre caciques por el deslinde

50 Conocidas son las denuncias del cronista don Felipe Guaman Poma de Ayala contra los curas doctrineros, quienes sistemáticamente se inmiscuían fuera de sus oficios en jurisdicción de corregidores y caciques, comportándose como "señores absolutos" para cometer soberbios abusos contra los indios tributarios (Guaman Poma 1615: 566 [580], 569 [583], 578 [592], 592 [606]). Particular atención merecen las conductas desmedidas del clero regular, personalizadas en la figura del mercedario fray Martín de Murúa, quien oficiara como cura del pueblo de Capachica en la ribera norte del lago Titicaca en las últimas décadas del siglo XVI (Guaman Poma 1615: 643 [657]-649 [663]; ÁlvarezCalderón Gerbolini 2004). de una estancia ganadera; un cura gestionando la excarcelación de un cacique; otro imponiéndose sobre un cacique que había levantado cargos en su contra; una posible alianza entre el cura y el cacique en torno al culto cotidiano; y el pronunciamiento de un importante cura sobre el desempeño de los caciques en el entero de la mita de Potosí.

¿Qué factores intervinieron en el armado de cada situación? ¿Existieron otras posibles articulaciones? ¿Cuán amplio y diverso habrá sido el abanico de posibilidades? Frente a estos interrogantes, nuestra propuesta se orienta hacia el análisis de la construcción de vínculos entre los distintos actores políticos responsables de la materialización del dominio colonial a escala local: el corregidor, el cacique y el cura doctrinero. El estudio de estas trayectorias (paralelas, convergentes $y / 0$ divergentes, dependiendo de la coyuntural correlación de fuerzas) puede informar en torno al rol que cada actor político supo ocupar en el escenario regional, teniendo en cuenta los distintos puntos de partida y las distintas estrategias de acumulación de capital (económico y político, pero también social y simbólico) para la construcción y reproducción de sus respectivos liderazgos y carreras, ejercidos sobre sus respectivos colectivos de pertenencia en cada contexto. En efecto, esas trayectorias pueden ser pensadas como caminos que construyeron un espacio político a escala regional, es decir, atendiendo al diseño de redes de relaciones tramadas a lo largo de los años de ejercicio de sus respectivos oficios, que explican históricamente la configuración del dominio colonial en la región; entendemos, pues, que el poder se territorializó a través de esas redes.

¿Qué vínculos se tejieron entre el proceso de cristianización de la población nativa y la construcción de estas redes de poder? Andadas varias décadas de dominio colonial, la cristianización de la población nativa, lejos de adecuarse al canon tridentino, cristalizó en un modo particular de ejercicio de la religiosidad, un modo específicamente andino (o altiplánico), que podríamos denominar "cristianismo aymarizado" o "cristianismo andino colonial" (Farriss 1992 [1984]; Stern 1986 [1982]). El desarrollo de este cristianismo local permitió a los líderes étnicos redefinir sus criterios de legitimidad; a los curas doctrineros, perseguir sus propias carreras político-eclesiásticas; y a la "gente del común", reconfigurar los sistemas de creencias una vez "superado" el traumatismo de la conquista. En tanto intermediarios 
culturales, los caciques y los curas encontraron las formas de habitar esa "zona de contacto" entre varios sistemas de creencias, "aymarizando" el cristianismo en términos de religión local (Christian 1991; Taylor 2000).

Así, la conquista espiritual, a través de la evangelización en tanto producción de nuevas subjetividades coloniales, devino en un proceso de redefinición de pautas de sociabilidad $y$, en el caso de los curas doctrineros y de los caciques, en una compleja instancia para legitimar sus liderazgos, toda vez que ambos actores debieron instaurarse como interlocutores válidos a partir de esa misma interacción. En tanto unos y otros se erigieron como referentes locales, como nodos convergentes de un conjunto de redes personales, el estudio de la tríada cura-cacique-corregidor desde una perspectiva sociopolítica constituye una clave analítica para entender las configuraciones del poder local.51 Buscamos,

51 En cuanto al corregidor, la normativa limitaba su mandato entre pues, reconstruir estas redes de intermediación sociopolítica porque consideramos que constituyen el entramado básico sobre el cual se operaron, eventualmente, los procesos de intermediación cultural.

Agradecimientos Una versión anterior de este trabajo fue presentada en las VI Jornadas Experiencias de la Diversidad, organizadas por el Centro de Estudios sobre Diversidad Cultural de la Facultad de Humanidades y Artes de la Universidad Nacional de Rosario, Argentina, los días 13 y 14 de agosto de 2015. Agradezco los comentarios y sugerencias que Nancy Egan, Silvia Mallo y Sara Mata me hicieran en aquella ocasión.

uno y tres años, lapso en el cual estos funcionarios debían insertarse en las redes de poder vigentes o articular otras nuevas (Lohmann Villena 1957).

\section{$\bullet$ Referencias citadas}

ADRIÁN, M. 1997. El espacio sagrado y el ejercicio del poder. Las doctrinas de Chayanta durante la segunda mitad del siglo XVII. Anuario del Archivo y Biblioteca Nacionales de Bolivia 3: 239-255.

ADRIÁN, M. 2000. Estrategias políticas de los curas de Charcas en un contexto de reformas y conflictividad creciente. Andes 11: 135-160

ÁlVAREZ-CALDERÓN GERBOLINI, A. 2004. Fray Martín de Murúa y su crónica: vida, obra y mentiras de un mercedario en los Andes (fines del siglo XVI-principios del XVII). Boletín del Instituto Riva-Agüero 31: 97-154.

AMSELLE, J.-L. 1985. Ethnies et espaces: pour une anthropologie topologique. En $A u$ Coeur de l'Ethnie: ethnies, tribalisme et Etat en Afrique, J.-L. Amselle y E. M’Bokolo (Dirs.), pp. 11-48. La Découverte, Paris.

ASSADOURIAN, C. S. 1983. El Sistema de la Economía Colonial. Nueva Imagen, México.

BARNADAS, J. 1993. Idolatrías en Charcas (1560-1620): datos sobre su existencia como paso previo para la valoración del tema de su extirpación. En Catolicismo y Extirpación de Idolatrías. Siglos XVI-XVIII, H. Urbano y G. Ramos (Comps.), pp. 89-104. Centro Bartolomé de Las Casas, Cuzco.
BARRIERA, D. G. 2006. Un rostro local de la Monarquía Hispánica: justicia y equipamiento político del territorio al sureste de Charcas, siglos XVI y XVII. Colonial Latin American Historical Review 15(4): 377-418.

BAUER, B. S. y C. STANISH. 2001. Ritual and Pilgrimage in the Ancient Andes. The islands of the Sun and the Moon. University of Texas Press, Austin.

BOUYSSE-CASSAGNE, T. 2005. Las minas del centro-sur andino, los cultos prehispánicos y los cultos cristianos. Bulletin de l'Institut Français d'Études Andines 34(3): 443-462.

CHOQUE CANQUI, R. 1993. Sociedad y Economía Colonial en el Sur Andino. Hisbol, La Paz.

CHOQUE CANQUI, R. 1998. Ayllus de la marka de Qaqayawiri. Estudios Bolivianos 6: 7-73.

CHOQUE CANQUI, R. 2003. Jesús de Machaqa: La marka rebelde. 1. Cinco siglos de historia. Plural-CIPCA, La Paz.

CHRISTIAN, W. A. 1991. Religiosidad Local en la España de Felipe II. Nerea, Madrid. 
COELLO DE LA ROSA, A. 2007. La doctrina de Juli a debate (15751585). Revista de Estudios Extremeños 63 (2): 951-990.

COELLO DE LA ROSA, A. 2011. El cabildo catedralicio y los jueces adjuntos en Lima colonial (1601-1611). Colonial Latin American Review $20(3): 331-361$.

COLE, J. A. 1985. The Potosi Mita 1573-1700. Compulsory Indian labor in the Andes. Stanford University Press, Stanford.

COOK, N. D. 1975. Tasa de la Visita General de Francisco de Toledo. UNMSM, Lima.

CRUZ, P. 2009. Huacas olvidadas y cerros santos. Apuntes metodológicos sobre la cartografía sagrada en los Andes del sur de Bolivia. Estudios Atacameños. Arqueología y Antropología Surandinas 38: $55-74$.

DOMÍNGUEZ FAURA, N. 2010. Para una cartografía de la lengua puquina en el altiplano colonial (1548-1610). Boletín de Arqueología PUCP 14:309-328.

DURSTON, A. 1999-2000. El proceso reduccional en el sur andino: confrontación y síntesis de sistemas espaciales. Revista de Historia Indígena 4: 75-101.

DURSTON, A. 2007. Pastoral Quechua. The History of Christian Translation in Colonial Peru, 1550-1650. University of Notre Dame Press, Notre Dame.

ESPINOZA SORIANO, W. 1960. El alcalde mayor indígena en el virreinato del Perú. Anuario de Estudios Americanos 17: 183-300.

ESTENSSORO FUCHS, J. C. 2003. Del Paganismo a la Santidad. La incorporación de los indios del Perú al catolicismo. 1532-1750. PUCPIFEA, Lima.

FARRISS, N. 1992 [1984]. La Sociedad Maya bajo el Dominio Colonial. La empresa colectiva de la supervivencia. Alianza, Madrid.

FINEGAN, C. P. S. 1999. Priests, Parishioners, and the Pastoral Visita: The moral economy of village life in the diocese of La Paz, 1680-1730. Ph.D. Dissertation, University of Florida.

GISBERT, T. 1980. Iconografía y Mitos Indigenas en el Arte. Gisbert y Cía., La Paz.

GLAVE, L. M. 2010. La provincia de Chucuito y sus caciques. El contexto de la correspondencia entre Diego Chambilla y Pedro Mateos. En Pleitos y Riqueza. Los caciques andinos en Potosí del siglo XVII, X. Medinacelli y M. Inch (Coords.), pp. 465-486. ABNB, Sucre.
GONZÁLEZ, R. 2010. Las iglesias y los pueblos reduccionales en Chucuito. En Chucuito. Fragmentos de una historia, R. González (Ed.), 20-31. FFyL-Universidad de Buenos Aires, Buenos Aires.

GONZÁLEZ, R. 2014. El Juli jesuítico. ¿Modelo misional o proyección historiográfica? IHS. Antiguos Jesuitas en Iberoamérica 2(1): 85100.

GUAMAN POMA DE AYALA, F. 1615. Nueva Corónica y Bueno Gobierno, J. V. Murra, R. Adorno y J. L. Urioste (Transcrips.). Disponible en: http://www.kb.dk/permalink/2006/poma/info/es/ frontpage.htm

HESPANHA, A. M. 1989. Visperas del Leviatán. Instituciones y poder político (Portugal, siglo XVII). Taurus, Madrid.

HIDALGO LEHUEDÉ, J. 2011. Redes eclesiásticas, procesos de extirpación de idolatrías y cultos andinos coloniales en Atacama. Siglos XVII y XVIII. Estudios Atacameños. Arqueología y Antropología Surandinas 42: 113-152.

HIDALGO LEHUEDÉ, J., M. MARSILLI C. y J. AGUILAR H. 2016. Redes familiares, carreras eclesiásticas y extirpación de idolatría. Doctrina de Camiña, Tarapacá. Siglo XVII. Chungara. Revista de Antropología Chilena 48(3): 409-428.

JURADO, M. C. 2004. Las reducciones toledanas a pueblos de indios: aproximación a un conflicto. El repartimiento de Macha (Charcas), siglo XVI. Cahiers des Amériques Latines 47(3): 123-137.

LOHMANN VILLENA, G. 1957. El Corregidor de Indios en el Perú bajo los Austrias. Ediciones Cultura Hispánica, Madrid.

LÓPEZ BELTRÁN, C. 1998. Alianzas Familiares. Elite, género y negocios en La Paz, S. XVII. IEP, Lima.

LUNDBERG, M. 2011. Church Life between the Metropolitan and the Local. Parishes, Parishioners and Parish Priests in Seventeenth-Century Mexico. Iberoamericana-Vervuert, Madrid.

MÁlAGA MEDiNA, A. 1974. Las reducciones en el Perú (15321600). Historia y Cultura 8: 141-127.

MARTÍNEZ LÓPEZ-CANO, M. P. 20o1. La Génesis del Crédito Colonial. Ciudad de México, siglo XVI. IIH-UNAM, México.

MAURTÚA, V. M. 1906. Juicio de Límites entre Perú y Bolivia. Imprenta Hernández, Madrid.

MEIKLEJOHN, N. 1988. La Iglesia y los Lupaqas durante la Colonia. Centro Bartolomé de Las Casas, Cusco. 
MILLS, K. 2004. In between: thoughts on cultural mestizaje in the colonial Andes and beyond. Ponencia presentada en el World History Workshop Series, Department of History, University of British Columbia, 26 de noviembre.

MORRONE, A. J. 2010. Clero rural y liderazgo étnico en el corregimiento de Pacajes: la antigua iglesia de Jesús de Machaca (siglo XVII). Anuario de Estudios Bolivianos, Archivísticos y Bibliográficos 16: $445-475$.

MORRONE, A. J. 2012. De "señores de indios" a nobles rentistas: los encomenderos de La Paz (1548-1621). Surandino Monográfico, Segunda Sección de Prohal Monográfico 2(2) http://www.filo.uba. ar/contenidos/investigacion/institutos/ravignani/prohal/mono. html

MORRONE, A. J. 2013a. Curas doctrineros y caciques andinos en la construcción de legitimidades: las iglesias rurales de La Paz (Audiencia de Charcas, 1570-1630). Jahrbuch für Geschichte Lateinamerikas 50: 29-54.

MORRONE, A. J. 2013b. Estrategias estatales y liderazgo étnico en el corregimiento de Pacajes (1538-1620). En Aportes Multidisciplinarios al Estudio de los Colectivos Étnicos Surandinos. Reflexiones sobre Qaraqara-Charka tres años después, A. M. Presta (Ed.), pp. 343372. IFEA-Plural, Lima-La Paz.

MORRONE, A. J. 2015. Tras los pasos del mitayo: la sacralización del espacio en los corregimientos de Pacajes y Omasuyos (15701650). Bulletin de l'Institut Français d'Études Andines 44(1): 91-116.

MURRA, J. V. 1988. El aymara libre de ayer. En Raíces de América. El mundo aymara, X. Albó (Comp.), pp. 51-73. Alianza, Madrid.

NALLE, S. T. 1992. God in La Mancha. Religious Reform and the People of Cuenca, 1500-1650. John Hopkins University Press, Baltimore.

NIELSEN, A. E. 2006. Plazas para los antepasados: descentralización y poder corporativo en las formaciones políticas preincaicas de los Andes circumpuneños. Estudios Atacameños 31: 63-89.

PÄRSSINEN, M. 2005. Caquiaviriy la Provincia Pacasa. Desde el altoformativo hasta la conquista española (1-1533). CIMA, La Paz.

PRESTA, A. M. 2000. Encomienda, Familia y Negocios en Charcas Colonial. Los encomenderos de La Plata, 1550-1600. IEP, Lima.

RAMOS, G. 1993. Política eclesiástica y extirpación de idolatrías: discursos y silencios en torno al Taqui Onqoy. En Catolicismo y Extirpación de Idolatrías. Siglos XVI-XVIII, Charcas, Chile, México, Perú, G. Ramos y H. Urbano (Comps.), pp. 137-168. Centro Bartolomé de las Casas, Cusco.
RAMOS, G. 2010. Muerte y Conversión en los Andes. Lima y Cuzco, 15321670. IEP-IFEA, Lima.

RAMOS, G. 2015. Sacred boundaries: parishes and the making of space in the colonial Andes. En From Dust to Digital. Ten years of the Endangered Archives Programme, M. Kominko (Ed.), pp. 225-258. Open Book Publishers, Cambridge.

RIVERA CUSICANQUI, S. y T. PLATT. 1978. El impacto colonial sobre un pueblo pakaxa: la crisis del cacicazgo de Caquingora (urinsaya), durante el siglo XVI. Avances 1: 101-120.

ROSTWOROWSKI, M. 2003. Peregrinaciones y procesiones rituales en los Andes. Journal de la Société des Américanistes 89(2): 97-123.

SACK, R. D. 1986. Human Territoriality. Its Theory and History. Cambridge University Press, Cambridge.

SAIGNES, T. 1984. Las etnias de Charcas frente al sistema colonial (Siglo XVII). Ausentismo y fugas en el debate sobre la mano de obra indígena, 1595-1665. Jahrbuch für Geschichte von Staat, Wirtschaft und Gesselchaft Lateinamerikas XXI: 27-75.

SAIGNES, T. 1987. De la borrachera al retrato: los caciques andinos entre dos legitimidades (Charcas). Revista Andina 5(1): 130-170.

SALLES, E. C. 2001. Cuestiones sobre Chucuito en el siglo XVI. Las exacciones de la Iglesia. En América bajo los Austrias, economía, cultura y sociedad, H. O. Noejovich (Ed.), 133-140. PUCP, Lima.

SALLES-REESE, V. 1997. From Viracocha to the Virgin of Copacabana. Representations of the sacred at lake Titicaca. University of Texas Press, Austin.

STERN, S. J. 1986 [1982]. Los Pueblos Indígenas del Perú y el Desafío de la Conquista Española. Huamanga hasta 1640. Alianza, Madrid.

STERN, S. J. 1987. La variedad y ambigüedad de la intervención indígena andina en los mercados coloniales europeos: apuntes metodológicos. En La Participación Indígena en los Mercados Surandinos. Estrategias y reproducción social, siglos XVI-XX, O. Harris, B. Larson y E. Tandeter (Comps.), pp. 281-312. CERES, La Paz.

TAYLOR, W. B. 1999 [1996]. Ministros de lo Sagrado. Sacerdotes y feligreses en el México del siglo XVIII. El Colegio de Michoacán, Zamora.

TAYLOR, W. B. 2000. La Iglesia entre la jerarquía y la religión popular: mensajes de la zona de contacto. En Historia de América Latina, B. F. Connaughton (Ed.), I: pp. 177-226. UNAM, México.

WACHTEL, N. 2001 [1990]. El Regreso de los Antepasados. Los indios urus de Bolivia, del siglo XX al XVI. FCE, México. 
WERNKE, S. A. 2007. Negotiating community and landscape in the Peruvian Andes: a transconquest view. American Anthropologist 109(1): 130-152.

ZAGALSKY, P. C. 2013. Tensiones, disputas y negociaciones en torno a la posesión de la tierra. Un mapeo histórico del espacio de los visisa. Andes meridionales, 1570-1610. En Aportes Multidisciplinarios al Estudio de los Colectivos Étnicos Surandinos. Reflexiones sobre Qaraqara-Charka tres años después, A. M. Presta (Ed.), pp. 191-227. IFEA-Plural, Lima-La Paz.
ZULOAGA RADA, M. 2012. La Conquista Negociada: Guarangas, autoridades locales e imperio en Huaylas, Perú (1532-1610). IFEAIEP, Lima. 